\title{
在线课程与翻转课堂相结合的大学化学混合式教学实践
}

邱海霞 ${ }^{*}$, 杨秋华, 曲建强, 李珅, 马亚鲁

天津大学理学院, 天津 300354

摘要: 介绍了自2017年以来天津大学大学化学课程使用在线课程和翻转课堂相结合的混合式教学实践, 包括课程的 组织模式、翻转课堂内容的选择、翻转课堂课时与课程总课时的比例、期末成绩分析和教学反思等。教学实践结果 显示, 选取学生在中学化学有一定基础的知识点作为教学内容, 课时占课程总课时的 $30 \%-50 \%$ 时进行翻转课堂教 学, 教学效果明显好于完全传统教学的平行对照班。

关键词: 大学化学; 翻转课堂; 在线课程; 混合式教学

中图分类号: G64; O6

\section{Blended Teaching Practice of Online Course and Flipped Classroom in College Chemistry}

Haixia Qiu *, Qiuhua Yang, Jianqiang Qu, Shen Li, Yalu Ma

School of Science, Tianjin University, Tianjin 300354, P. R. China.

\begin{abstract}
This paper introduces the blended teaching practice of flipped classroom based on online course in college chemistry in Tianjin University since 2017, including the organization mode of teaching process, the selection of flipped leaning content, the proportion of flipped learning time in total class hours, the final test scores analysis and teaching reflection. In this study, flipped class hours accounted for $30 \%-50 \%$ of the total class hours and teaching content in which students had already accumulated some basic knowledge during middle school were selected in flipped classroom. The result showed that the teaching effect of flipped classroom was superior to that of traditional parallel class.
\end{abstract}

Key Words: College chemistry; Flipped classroom; Online course; Blended teaching

天津大学大学化学课程面向全校机械、建工、环境、自动化、精仪、海洋等学院的十多个专业 开设。为满足全校不同专业学生对化学知识的需求, 课程组开设了中文、双语、全英文、必修、选 修等不同类型、不同学时的大学化学课程。在天津大学教务处的大力支持下, 天津大学大学化学团 队精心设计教学内容, 于 2017 年初建成了大学化学中文在线课程, 包括视频、演示实验、课件、 测试题、拓展资料等。2017 年和 2018 年分别在智慧树(用于本校学生进行翻转课堂)和中国大学 MOOC 平台上线(面向社会大众)。目前已运行三个学期, 有几十所高校选课, 累计选课人数近万人。 翻转课堂是一种新型教学模式, 通过对知识传授的颠倒安排, 改变了传统教学中的师生角色。这种 参与式教学将学习的决定权从教师转移给了学生, 可以有效提高学生的自主学习能力和独立分析问 题的能力 ${ }^{[1-5]}$ 。2017 年春季开始, 课程团队利用在线课程资源在 32 学时的中文班级开展了在线课程

收稿: 2019-06-10; 录用: 2019-07-20; 网络发表: 2019-08-06

“通讯作者, Email: qhx@tju.edu.cn

基金资助: 天津大学在线开放课程建设项目 
与翻转课堂相结合的混合式教学实践。混合式教学作为课堂教学和网上辅助教学形成的一种混合模 式, 可以充分调动学生的学习积极性, 一些教师在无机化学、大学化学、物理化学、食品化学等课 程中进行了混合式教学实践 ${ }^{[6-10]}$, 但大多探讨的是混合式教学的组织模式。笔者主要探索了天津大 学大学化学课程混合式教学中教学内容的选择、课时比对教学效果的影响, 以及在课程组织中如何 有效发挥学生的主动性。

\section{1 课程的组织模式}

大学化学 32 学时的课程设置为: 每周 1 次课, 1-16 周开设, 共 16 次课。在混合式教学实践的 章节中, 采用学生线上自主学习和线下师生见面课交替的方式进行(即: 上一周学生自行线上学习, 下一周为线下师生见面课)。

\section{1 学生线上学习}

为了保障学生线上学习的有效实施, 需要教师和学生分别完成各自的任务(见表 1)。个体任务和 团队任务的设置, 锻炼了学生的自主学习能力和团队协作能力。为了保障下次见面课时课堂讨论的 有效开展, 要求学生根据线上学习情况将不懂的问题提前发至平台的论坛上, 以便每个团队中负责 回答问题的同学能提前做准备，同时也可以让全班其他同学提前思考。

\section{表 1 学生线上学习中教师和学生的任务}

\begin{tabular}{ll}
\hline 角色 & \multicolumn{1}{c}{ 任务 } \\
\hline 教师 & 将学生分组 (5-6 个学生一组), 提前布置小组团队任务和学生的个体任务, 并给出评分标准 \\
& 对团队任务中每组的 PPT 和讲稿进行修改, 提出修改意见并作适当指导 \\
& 鼓励学生在课程平台的讨论区发言, 对讨论区学生的问题给予引导和适当提示 \\
& 根据学生的观看视频进度, 利用平台的提示功能督促学生学习 \\
学生 & 个体任务: 根据个人基础观看下次见面课所涉及的视频、课件、拓展资料等课程资源, 做平台上的测试, 将不懂的问题提前 \\
& 发至在论坛上 \\
& 团队任务: 组长对组员进行合理分工, 每组负责 3-5 个视频知识点的提炼和答疑, 并在见面课上进行 PPT 展示
\end{tabular}

\section{2 线下见面课}

在翻转课堂实施过程中, 比学生线上学习更重要的是如何有效地设计见面课。见面课包括: 小 组 PPT 展示、学生提问、全班讨论、教师补充拓展内容和总结。每组学生就所承担的视频内容进行 PPT 汇报的时间约 $10 \mathrm{~min}$, 讨论时间约为 $20 \mathrm{~min}$ 。为了保证学生 PPT 展示的质量, 教师须对学生提 炼的知识点和做的 PPT 进行严格把关, 督促其在课下进行演练。在课堂上, 教师应充分发挥组织和 协调作用，鼓励班里学生积极提问和讨论，并适当辅之以教师的提问。

\section{3 成绩评价}

学生在翻转课堂部分的成绩计入整个课程的总评成绩, 由线下章节测试、PPT 展示、讨论发言 三部分组成。这三部分的评价标准和成绩权重见表 2。

\section{2 翻转课堂内容的选择}

大学化学的授课对象是大学一年级的新生, 中学新课程改革将高中化学设置为必修模块和选修 模块。由于对选修模块的选学方式不同, 不同省市的学生在学习大学化学课程时起点差别很大。天 津大学大学化学课程 32 学时的主要内容包括: 化学热力学、溶液与离子平衡、氧化还原与电化学、 结构化学基础、配位化合物、化学与材料等。高中化学必修模块涉及到的溶液与离子平衡、氧化还 原与电化学, 学生有一定的基础, 接受起来容易; 化学与材料部分的特点是涉及内容广, 但难度不 大, 学生也感兴趣。因此在翻转课堂内容的选择上, 选取了以上三章内容用于翻转课堂教学。 
表 2 翻转课堂的成绩评价标准和成绩权重

\begin{tabular}{|c|c|c|}
\hline 评价内容 & 评价方法 & 成绩权重 $/ \%$ \\
\hline 章节测试 & 线下进行统一的闭卷考试 & 15 \\
\hline PPT 展示 & $\begin{array}{l}\text { 教师给出 PPT 制作、讲解、提问、答问等环节的评分标准和分值, 并对每组评分, 教师评分权重占 } 40 \% \text {; } \\
\text { 每组出一个评委, 评委须对每组展示进行具体点评, 每组得分为去掉最高分和最低分后的平均值, 学 } \\
\text { 生评分权重占 } 60 \%\end{array}$ & 10 \\
\hline 讨论发言 & 线上讨论区发帖+线下课堂发言 & 5 \\
\hline
\end{tabular}

“结构化学基础” 部分难度较大, 学生由于在高中的选修方式不同, 基础差别大, 传统课堂无 法满足学生的需求, 而完全采用翻转课堂则基础差的学生学习起来吃力。采取翻转课堂和传统授课 结合的方式可以有效解决由于高中化学选修模式不同带来的教学难题。这部分内容中将价键理论、 分子间作用力和氢键等高中化学选修课中涉及到的知识点采用翻转课堂方式授课, 让高中选修过该 模块的学生提炼知识点, 这些学生在准备过程中不仅锻炼了能力, 而且能对知识进行更深层次的思 考; 高中没有选修过该模块的学生通过线下观看视频提前熟悉相关知识点。这一章的其他部分内容 如波函数和量子数、多电子原子结构、杂化轨道理论、分子轨道理论等由教师采用传统授课的方式 讲解。

\section{3 教学效果}

2017 年春季在应用物理专业的 2 个班中(每个自然班 30 人)进行了翻转课堂实践, 机制专业 4 个班采用传统授课模式, 作为对照组。翻转课堂教学的学时占课程总学时百分比为 $30 \%$ 。表 3 是 2017 年春季大学化学课程采用翻转课堂和传统课堂期末考试裸分分布。和传统授课模式的班级相比, 应 用物理专业的平均成绩提高了 6.1 分，大于 90 分的高分段人数百分比提高了近 10\%, 80-89 分段的 人数提高了 $12.9 \%$, 不及格率降低了 $5.1 \%$ 。机制专业每年的高考招生成绩高于应用物理专业, 可以 排除生源的影响。

表 32017 年春季大学化学课程(32 学时)翻转课堂和传统课堂期末考试裸分分布

\begin{tabular}{ccccccc}
\hline 专业 & 平均分 & $>90$ 分 $/ \%$ & $80-89$ 分 $/ \%$ & $70-79$ 分 $/ \%$ & $60-69$ 分 $/ \%$ & 不及格率 $\%$ \\
\hline 应用物理1-2班 & 71.3 & 13.3 & 30.0 & 21.7 & 11.7 & 23.3 \\
机制1-4班 & 65.2 & 3.4 & 17.1 & 25.0 & 26.1 & 28.4 \\
\hline
\end{tabular}

2017 年秋季增加了翻转课堂的教学内容, 翻转课时/课程总学时比提高到 $50 \%$, 并把实施翻转 课堂教学的班级由春季的 2 个班增加至 7 个班。表 4 是 2017 年秋季大学化学课程 32 学时采用翻转 课堂和传统教学期末考试裸分分布。表 4 的期末裸分数表明, 将翻转课堂的教学学时提高至 $50 \%$ 后, 翻转课堂教学班级大于 90 分的人数增加了 $7.8 \%$, 不及格率降低了 7\%, 80-89 分段的人数和平均分 区分度不太大, 说明提高翻转课堂的教学学时更有利于自律能力强的高分段学生学习成绩的提高。

\section{4 体会与反思}

\section{1 翻转课堂和传统课堂的课时比要适当}

期末考试成绩只是教学的一部分, 为了了解学生在学习过程中的体会和建议, 课程结束后对学 生进行了无记名问卷调查, 结果见表 5。赞成翻转课堂和传统教学结合的学生比例达 $96.6 \%$, 学生 只是在翻转课堂的课时上存在分歧, 说明适当课时的翻转课堂是受学生欢迎的。由于过多的翻转课 堂教学会增加学生的学习负担, 翻转课堂占总学时比 $30 \%$ 的学生赞成百分比为 $53.3 \%$, 当翻转课堂 
表 42017 年秋季大学化学课程(32 学时)翻转课堂和传统课堂期末考试裸分分布

\begin{tabular}{|c|c|c|c|c|c|c|}
\hline 专业 & 平均分 & $>90$ 分 $/ \%$ & $80-89$ 分 $/ \%$ & 70-79分 $/ \%$ & 60-69分/\% & 不及格/\% \\
\hline 土木 $1-3$ 班 & 70.9 & 7.1 & 21.2 & 29.3 & 27.3 & 15.1 \\
\hline 工程实验班1-2班 & 78.2 & 15.7 & 45.1 & 13.7 & 13.7 & 11.7 \\
\hline 建环1-2班 & 74.8 & 15.6 & 43.8 & 12.5 & 15.6 & 12.5 \\
\hline 翻转班平均成绩 & 74.6 & 12.8 & 36.9 & 18.5 & 18.8 & 13.1 \\
\hline 传统教学 2 个对照班 & 73.6 & 5.0 & 38.3 & 21.7 & 15.0 & 20.0 \\
\hline
\end{tabular}

表 5 翻转课堂课时比的无记名问卷调查结果

\begin{tabular}{ccccc}
\hline 翻转课时 $/$ 课程总学时百分比 $/ \%$ & 0 & 30 & 50 & 70 \\
\hline 问卷调查学生赞成的百分比 $/ \%$ & 3.4 & 53.3 & 30.0 & 13.3 \\
\hline
\end{tabular}

占总学时比 $70 \%$ 时, 学生赞成的百分比只有 $13.3 \%$ 。这说明翻转课堂不能完全取代传统课堂, 需要 教师进一步思考如何将翻转课堂和传统课堂有效结合, 并针对不同的学习群体, 采取多元化的教学 方法。

\section{2 线上学习要分级教学}

由于中学化学新课标改革, 不同省份学生的化学基础有差别, 还有的学生参加过全国中学生化 学竞赛。要求学生根据自己中学化学的基础有选择性地观看视频, 无须要求所有学生的观看进度都 一样, 否则学生会为了成绩刷视频, 达不到预期的效果。基础好的学生对视频观看量不做特别要求, 要鼓励他们在讨论环节积极参与, 提出高质量的问题。

\section{3 线下见面课 PPT 展示要有效}

如何提高见面课上学生 PPT 汇报的听课率并有效展开讨论是翻转课堂实施的关键。需要教师课 前对学生 PPT 进行严格把关, 多次修改, 指导学生设计互动环节, 对负责讲解 PPT 的学生进行指导。 翻转课堂对自主学习能力强的学生有效, 但对自主学习能力差的学生, 尽管有教师督学和章节测试 作为手段, 但仍有学生线上不主动看视频, 见面课课堂吸收效果较差, 需要教师投入精力进行引导。

\section{参 考 文 献}

[1] Scott, A. R. Chem. Educ. Res. Pract. 2016, 17 (4), 914.

[2] 周明娟, 张颖, 于苗, 菅文平. 大学化学, 2018, 33 (11), 67

[3] 苏小红, 赵玲玲, 叶麟, 张彦航. 中国大学教学, 2015, No. 7, 60 .

[4] 陈云, 高英, 吴庆生. 大学化学, 2017, 32 (11), 7.

[5] 刘敏, 唐乾, 冯清. 大学化学, 2018, 33 (11), 22.

[6] 马骁飞, 马亚鲁, 田昀, 秦学, 高洪苓, 刘华姬, 鲁凡丽. 大学化学, 2018, 33 (11), 15 .

[7] 李文旭, 张立珠, 肖金礼, 唐冬雁, 强亮生. 大学化学, 2015, 30 (3), 18.

[8] 王旭珍, 王新平, 王新葵, 宋雪旦, 田东旭, 陈冰冰, 石川, 纪敏, 大学化学, 2018, 33 (11), 6 .

[9] 张雯, 高培红, 向丹, 唐玉海, 大学化学, 2018, 33 (1), 24.

[10] 周静峰, 何雄. 化学教育, 2018, 39 (22), 53 . 